\title{
Elements of ecological architecture in Theologos: a traditional settlement on Thassos Island, Greece
}

\author{
K. Lantitsou \& B. Stefanis \\ Transport Work and Transports Sector Department of Civil Engineers, \\ Polytechnic Faculty, Dimokritus University of Thrace (DPTH), Greece
}

\begin{abstract}
The aim of this work is the enhancement of ecological planning principles and manufacturing through the study of traditional architecture. Thassos is the northernmost island of the Aegean Sea, mountainous with rich vegetation, history and culture; the only Aegean island where we see the traditional Macedonian and Thracian building methods of the hinterland, with certain local peculiarities that concern mainly construction techniques and habits. The mountainous settlement of Theologos preserves many of the south oriented traditional buildings, built entirely from stone or from a combination of stone and timber. Their roofs are usually covered with slates. Building materials, such as stones and slates, are excavated from nearby regions, while wood is taken from pine trees found everywhere in the region. The village streets are paved while particular architectural interest is present in the churches. It is worth mentioning that the entire settlement has elements of ecological urban planning; south oriented while the north is protected from the mountain range and also the organization of space in to parishes - neighbourhoods with a complete community way of life. Furthermore, inside the community in the middle of the 20th century, a self-reliant local growth existed, following ecological development principles. It can be said that this traditional settlement demonstrates the principles of ecological development and ecological planning, but mainly, the principles of ecological architecture within a local tradition.

Keywords: ecological architecture, traditional settlements.
\end{abstract}




\section{Introduction}

Many Greek villages still preserve the traditional way of life to a high degree. "These villages remind us of the beauty and the robustness of old customs based on self-reliance and the resistibility that life always requires", reports H. Skolimonski in his book "Ecological philosophy, a new tactic in life". Such a village, Theologos, lies in Thassos, a north Aegean verdurous island. The climate is temperate with many beautiful forests and abundant waters. Theologos is a traditional mountain traditional settlement located in the south department of the island. Its high aesthetic value houses are built with local stone, gathered by the residents themselves, and the whole village is aesthetically incorporated in to the wider environmental area.

The ecological and cultural sensitivity that exists in the architecture of each house also exists in the urban organization of the village. These are examples of a culture that has evolved in this region, a culture that respects both humans and nature. Until the middle of the previous century, the village and its wider area, as a community, were financially and socially self-reliant. It could have also been considered as a model of ecological development and ecological planning.

\section{Ecological architecture and tradition}

Theologos is built on the edge of a mountain range. The ancient village walls and other artifacts certify the existence of a settlement at least from the Roman era. Until 1840, Theologos was the largest village on the island. Up to 1960, it was a financially and socially self-reliant settlement, and nowadays it maintains its rich culture, morals and customs. During the last decades many of its residents abandoned the village and moved to the coastal settlement of Potos, a small fishing village; a small port that from early 70 s has rapidly developed its tourism industry. Nowadays, Theologos numbers 1700 residents. The village is south oriented while from the north it is protected by the mountains. It is crossed by two main streets with direction from $\mathrm{E} \rightarrow \mathrm{W}$, while vertical narrow alleys run from $\mathrm{N} \rightarrow \mathrm{S}$, some with a little bend to that direction to protect the walkers from northern winds.

The choice of the specific location, the orientation and the organization of the settlement shows that its residents had empiric knowledge of ecological planning. It is a well-known fact that the climates of a region as well as the natural elements that surround a settlement (forest, mountains, landscape etc.) are ecological urban planning parameters.

Village houses built with materials found in the nearby region are fully harmonized with their natural environment. Most houses are two-floored, entirely stone-built, while there are some houses that the first floor south wall usually - is built with a concealed wood skeleton (tsatmas) [1].

Ecological architecture elements are used for the construction of each house, the knowledge of which has been handed down from generation to generation. Judging by the way that the residents of Theologos planned and built their houses they tried empirically to exploit solar energy for heating and natural 
lighting of their houses during winter and cool winds for their natural cooling in summertime. Almost all houses are south oriented while a few have a small divergence from south up to $\pm 25^{\circ}$.

Due to the intense slope of the ground, the ground floor entrance of each house is always to the south; from the North it was underground. This space is usually used for food storage in villas while in other houses either as a shop or residence. Houses that are built entirely with stone had a rectangular ground plan and a symmetrical view with a balcony in the middle of the south view and windows at both sides in order to collect solar radiation for heating and lighting. A venetian blind called a pergola (special wooden or iron structure covered with arbour or climbing plants during spring and summertime) provide sun protection for the first floor balcony. In the northern wall of the house there were small openings used for creating currents to cool the area. Most rest areas are mainly placed in the southern side of the building. Commonly in houses located in the northern area, the storage or stable areas were placed behind the main residence area, which was thus protected from cold.

Many houses had a courtyard to the North used in the summertime. Within a few meters of the building, and after the courtyard, there was a line with a garden elevated at two meters, and then other auxiliary buildings such as observatories (buildings where they stepped on the grapes in order to produce wine), stables for their animals and ovens for cooking their bread. This line of auxiliary spaces protected the house and the north courtyard from northern winds.

The exterior stonewalls of the buildings were 60 to $80 \mathrm{~cm}$ thick. The heat insulation factor was clearly higher than the one found in today's walls. The internal walls of the buildings were constructed with a wooden skeleton and wooden coated laths (bagdati). This way of building ensures flexibility in the building and makes it durable in earthquakes. Often dark boards are used for the wooden floors and ceilings to obtain maximum absorption of solar radiation. This contributes in faster heating of the internal space.

Slates are used to cover the roofs (plates removed from mountain behind the village). The sloped roof ensures the removal of rain from the residence, but also offers also an essential reduction of thermic loss from the loft that is the most exposed side of house. The air between the roof and the ceiling serves as an excellent insulator, both against the heat and the cold.

In the house's interior, a fireplace always existed in the room where the whole family was gathered. The good taste of the residents was well developed and the houses were aesthetically constructed. Their interior walls were decorated with traditional paintings, the ceilings were elaborate, and the furniture was beautiful while textiles are still famous for their beauty.

The second category of house is those built with a ground plan in the shape of ' $\Pi$ ', creating one central recess (liakoto), south oriented, as an area used for sunny days. The roof of the house is rectangular, ensuring the required shading of the "liakoto" in summertime. In other cases in the rectangular ground plan of the house there was a room as an appendix placed in the centre of the building or a corridor in the floor surrounded with big windows. During the winter, they closed the panes in order for the room to function as a greenhouse, while in the 
summertime they opened them creating a semi-outdoor covered space that is protected from the sun to that side of the building. Usually, this space protruded up to 60 or $100 \mathrm{~cm}$ from the building for aesthetic reasons. The section that stuck out was made of concealed wood wall (tsatma).

\section{Ecological elements in residential complex level}

The starting point for the construction of traditional settlements and houses begins with the choice of location using general criteria such as geomorphology, climatic conditions, existing natural resources and especially its position towards the sun, the wind and the proximity to water. The protection from the northern winds and the exploitation of southern orientation, where longer sunlight duration in winter is observed, natural fresh air currents, the constant soil and the high vegetation and also the natural sources of water have been valued as virtues of good locality. Theologos as a residential complex reclaimed to the maximum extend the existing natural environment conditions. Its residents having perceived the advantages of a sun-oriented house built their properties being careful not to shade their neighbours, and creating the streets in such a way that served this principle.

While the central streets directed from $\mathrm{E} \rightarrow \mathrm{W}$, most narrow alleys between the houses and the courtyards had mapping from $\mathrm{N} \rightarrow \mathrm{S}$ with small divergences. Local stones were used to construct the streets and cobbled roads by the residents themselves.

The settlement was divided in to two districts with two highly aesthetic art architecture churches and a common school. Each house was financially selfreliant. Apart from the gardens of their residences, most residents also had gardens with vegetables and fruit bearing trees at the edge of the village. Abundant waters channeled with streams through the village in the gardens in the area; and still are.

Inhabitants of Theologos developed a high level of culture, integrating its own morals and customs, songs and dances. They had also developed the folklore arts to a high degree. Local textiles were pieces of art decorated with traditional drawings as well as their local costumes. Wood sculpture, including both ecclesiastical and domestic, have also been evolved. Local drawings are used for home decoration, painting and furniture.

Inhabitants had intensively developed a community. People were interested in one another. Living on an economy of "storage" rich people gave food to the poor having developed the feeling of solidarity. When a house was destroyed by fire, or by any other cause, they used their animals to transport building materials (stones, timber, etc.) from nearby regions and built the new house all together. Their knowledge of practical medicine was also impressive. Knowledge passed from generation to generation. They diligently took care of the sick using a wide variety of herbs grown in the area. 


\section{The role of vegetation in the traditional residence and in the settlement}

We know that the feeling of invigoration that appears to those who walk in a forest or in a mountain is attributed to the production of electricity due to friction caused by the wind when it blows on the trees, recharging the atmosphere with ions. The photosynthesis process in the forests and the ultraviolet radiation in the mountains create a revitalizing feeling for the human. A source near the house allows its users to benefit from the natural ionization caused by the raindrops (Lenard phenomenon). Three sides of the Theologos settlement are surrounded by rich forests, and it has abundant waters, providing a particularly healthy climate.

Apart from the existence of the peripheral forest there was also rich vegetation growth inside the village. All houses accommodated courtyards with gardens where they planted their vegetables and many fruit bearing trees for covering their domestic needs. Furthermore, these plants and the trees also helped considerably in the control of the temperature of the houses and consequently in the saving of energy. Plants and trees provide sun protection during summertime, absorb sound and noise, prevent the erosion of grounds and filter the exterior and interior pollutants of the buildings.

Theologos inhabitants using their empiric ecological knowledge had correctly used the terrain and vegetation for protection during the wintry months from the wind and the cold. During summertime, apart from the trees, pergolas also helped in the protection from the sun.

Plants, however, also have other beneficial characteristics. With fine weather conditions, plants and especially trees produce negative aromatic ions and "they capture" positive ions in order to lead them to the ground. The blowing of the wind between the trees also causes ionization. The presence of plants around a building is not only used for shading or aesthetic reasons but also for health reasons due to the "oxygen" that comes out from the trees that is precious for life. Theologos also has lots of water, running from almost right outside the courtyards of each house, with negatively charged ions that are also found near waterfalls or in level surfaces of clean water. All these conditions create a very healthy environment.

\section{Theologos as an ecological development model}

Ecological development provides new parameters in the productive and cultural activities of humans in relation to the laws of nature and the real needs of a person, such as intellectual, social and material ones. Ecological development sets as a horizon growth that in a certain time-space frame manages the natural resources according to the terms that nature determines, developing a strategy complying with the culture, the tradition of a country or a region and the internal moral values [2]. This particular village is easily characterized as an ecological development model. 
Theologos comes first in extent community of Thassos in the region of which is comes under the $1 / 3$ of the island. Within the community of Theologos are also the settlements of Potos, Astris, Thymonia, Aliki and Kinira.

Apart from the gardens near the village, families also had olive trees as well as farms with fruit bearing trees and vegetables, wheat, barley, maize etc. In many of those farms, and especially in olive groves, they had constructed small stone huts with local stones; an example of rural architecture. The community produced fine wines, oil, honey and dry fruits. Their agriculture was biological. They used the manure of their animals and fallen leaves for fertilizer. Their livestock farming was also biological. They had animals on free pasturage in the pasturelands. Apart from the cattle-breeders that practiced livestock farming as a profession, each household had its own animals producing milk, cheese and meat for the needs of the family. They produced the buckrams that they used. They spun and wove sheep's wool. Carpets (rugs) and blankets were woven by themselves and decorated with elaborate traditional drawings.

Pine and oak trees supplied marvelous timber for building lumber and for their boats. Apart from the pines, in the region abound planes, chestnuts, aromatic wicker, myrtle, rosemary, oregano, sage, thyme etc. The variety of flowers is huge and every summertime boats bring beehives and bees to the island. In the plains of the beach and in slopes with good orientation olives are been cultivated and, more infrequently, vines. The wine once was famous and exported to all Mediterranean basins. Exportable quality products were olives, olive oil, honey, wine, dry fruits, treacly sweets and textiles. In the crofts there were fruit bearing trees, such as apple, pear, peach, apricot and fig trees.

Apart from fruit bearing trees in the crofts, uncultivated plants were widespread. The soil, the climate, the abundance of waters, and the diligence of the residents had changed the region into an earthly paradise. Theologos was, as a society, an ecological development model.

\section{Conclusion}

We could say that the house of the future comes from the past. Bioclimatic planning today recognizes the regulating effect of topography, landscape, water, the ability that free spaces have to maximize or to minimize the infiltration of the sun and elects the important role of planning, aiming for the achievement of the desired objectives. The logic of planning in harmonious relation with the climate and the environment is an old perception. The old traditional settlements prove the talent of users/residents to originate ecological architecture.

The arrangement of houses, their adaptation, the terrain, the harmonization with the landscape and the exploitation of climatic advantages of geographic space, and the use of local ecological building materials for their construction prove the empiric ecological knowledge of the residents. In the continental departments of Greece, settlements have been developed in southern slopes of the mountains, so that the mountainous expanse behind functions as an inhibitor to the northern winds, while the openings of their houses face to the south. The 
local traditional architecture developed mainly from the need to face the changes of weather, the sun and the wind.

Thus in regions where stone abounded as building material they built stone houses. Stonewalls have thickness of 60 to $80 \mathrm{~cm}$, a fact that ensures the insulation of building and mild temperature changes. In a traditional house, winter and summer living spaces are designed for the better confrontation of climatic conditions. The summer spaces on the ground floor and their exterior stonework become "tsatma", with variants from region to region. In these spaces, big openings are placed to ensure sufficient airing, mainly during summertime. In the northern side of the buildings facilities such as the kitchen and warehouses are placed, with most rest spaces placed mainly in the southern side of the building.

In conclusion, we could say that the study of traditional offers important information on ecological architecture for modern urban planning. The principles of ecological layout, ecological architecture and urban planning that are located in the constructions of the past have the possibility to be adapted for modern needs. Greek settlements such as Theologos factually teach eco-development, as well as ecological urban planning and architecture.

\section{References}

[1] Papaioannou, K. , Kremezi, A., Fine, M., The Traditional House in Aegean, P.E. Micheli Foundation, Athens, pp. 22-23, 2001.

[2] Lantitsou K., Ecological Parameters in the Development and in the Planning of Space - A Greece Case, Doctorate Disquisition. Transport Work and Transports Sector Department of Civil Engineers, Polytechnic Faculty, Dimokritus University of Thrace, Xanthi, pp. 223-307, 1988. 